\title{
Strategic Guidance Model for Product Development in Relation with Recycling Aspects for Automotive Products
}

\author{
Muhamad Zameri Mat Saman (Corresponding author) \\ Faculty of Mechanical Engineering, Universiti Teknologi Malaysia \\ 81310 UTM Skudai, Johor, Malaysia \\ Tel: 60-19-779-6872 E-mail: zameri@fkm.utm.my
}

Feri Afrinaldi

Faculty of Engineering, Andalas University, Padang, Indonesia

Norhayati Zakuan

Faculty of Mechanical and Manufacturing Engineering, Universiti Tun Hussien Onn Malaysia

86400 Parit Raja, Batu Pahat, Johor, Malaysia

Gordon Blount

Faculty of Engineering and Computing, Coventry University

Priory Street, Coventry CV1 5FB, United Kingdom

Jane Goodyer

Institute of Technology and Engineering, Massey University

Palmerston North, New Zealand

Ray Jones \& Ashraf Jawaid

Faculty of Engineering and Computing, Coventry University

Priory Street, Coventry CV1 5FB, United Kingdom

The research is financed by Universiti Teknologi Malaysia (UTM).

\section{Abstract}

This paper discusses a strategic guidance model for the product development process of automotive components in order to fulfil the requirements of the recycling aspects in End-of-Life Vehicle (ELV) Directive. This proposed model will enable automotive designers to assess products for their technical and economic viability at end-of-life. The paper presents an example of the whole vehicle as a case study in order to demonstrate and validate the proposed framework. It argues that indicators from the analysis can be used to inform the strategic development plans of the vehicles, infrastructures and spare part businesses. Based on this concept, a design guidance model is presented in order to help the designer make a right decision in the product development process so that value can be maximised at a product's end-of-life.

Keywords: Strategic Guidance Model, Value Analysis, Financial Analysis, Payback Period, Automotive Recycling, End-of-Life Vehicle Directive, Automotive Design

\section{Introduction}

In recent years, environmental issues have become a priority for manufacturing companies. In particular, the automotive industry has taken a proactive stance due to legislative pressures. Legislation such as the End-of-Life Vehicle (ELV) Directive (The European Parliament and of the Council of European Union, 2000, 2002, 2005a, 2005b, 2005c, and 2008) 
has highlighted the need for automotive Original Equipment Manufacturers (OEMs) to design vehicles that can conform or, indeed, exceed ELV targets. At present, approximately $75 \%$ to $80 \%$ of end-of-life vehicles in terms of weight, mostly metallic fractions, both ferrous and non ferrous are being recycled. However, the remaining $20 \%$ to $25 \%$ in weight, consisting mainly of heterogeneous mix of materials such as resins, rubber, glass, textile, etc., is still being discarded (Toyota Motor Company, 2005).

EU ELV Directive forces the vehicle manufacturers to (The European Parliament and of the Council of European Union, 2000, 2002, 2005a, 2005b, 2005c, 2008):

1) Reduce the use of hazardous substances.

2) Design new vehicles that are easier to dismantle, reuse, recycle and recover components/materials/energy from vehicles that have been junked or totalled.

3) Increase the use of recycled materials in new vehicles.

The EU draft on ELVs also outlined that car manufacturers must reuse or recover $85 \%$ of ELV by 2006. Stating that at least $80 \%$ of a vehicle's weight must be reused or recycled; although up to $5 \%$ can be dealt with through other recovery operations such as incineration. This target increases to $95 \%$ by 2015 and at least $85 \%$ of that weight must be reused or recycled (The European Parliament and of the Council of European Union, 2000, 2002, 2005a, 2005b, 2005c, 2008). A summary of the general recycling targets, based on the ELV Directive, and recycling targets for the type-approval of new vehicles are shown in Table 1 and 2 respectively.

Currently most developed countries set legislation that will significantly change the way automotive OEMs and vehicle recycling companies (i.e. dismantlers and shredders) design and dispose of vehicles. This situation allows the recycling industry to play a more significant part in a vehicle's life cycle. The vehicle recycling business will be replaced by corporate recycling factories. It will move from spare parts to a raw materials business (PricewaterhouseCoopers, 2002).

In response to this, German and Holland authorities introduced the concept of 'Producer Responsibility', which obliged the car manufacturers to take back ELVs. This is to control the disposal of ELVs. The vehicle manufacturers decide to reduce the environmental burden of their products by improving the recyclability of cars. However, when the EU Directive stated that they must take back and treat ELVs at no cost to the last owner it generated intense opposition from the manufacturers, as they would have to assume a great financial cost (Kenari, Pineau and Shallari, 2003).

The introduction of the directive will affect all players involved in the management of ELVs in terms operational strategy, infrastructure and financial investment. The whole structure of automotive recycling is expected to change. The traditional dismantling techniques will become more advanced, as legislation demands the removal of all hazardous liquids and components. Also some form of plastics, rubber and glass recovery is necessary, either during the dismantling phase or during the separation process.

The directive has resulted in a plethora of research in the areas of design for recycling and into new techniques and technologies for vehicle disassembly (Desai and Mital, 2005). However, research has not focused on the strategic decisions automotive designers must make when they are designing vehicles for recyclability which, at the same time, can also minimise cost or maximise revenue when a vehicle comes to it's end-of-life. Based on this scenario, the body of this paper is to discuss a model of Strategic Guidance for vehicle design in relation with recycling and cost/value aspects. This model will enable automotive designers to assess the design of products for their technical and economic viability at end-of-life.

In this scenario, a rigorous Strategic Guidance model is needed for automotive design recyclability assessment to fulfil the requirement of the ELV Directive and at the same time to improve the design of the vehicle components in order to increase the value at end-of-life. The paper begins with a short description of literature in this area and follows this with a detailed explanation of the proposed model. After that, the paper presents a case study in order to demonstrate and validate the proposed model. Lastly, the results are discussed and conclusions drawn with recommendations for further research.

\section{Literature Review}

\subsection{Recycling Processes of ELVs}

The understanding of the recycling processes of ELVs is very important in the design of a new vehicle; it's sub-system and components. It can assist automotive designers to design new vehicles that are more economical and valuable at the end-of-life. These two aspects can be maximised if the vehicle can be disassembled and recycled easily. So in order to achieve this target, several stages in the recycling process must be clear defined.

An important stage of the recycling process is disassembly. Desai and Mital (2003) defined disassembly, in the engineering context, as organized process of taking apart a systematically assembled product (assembly of components). 
Disassembly process may be clearly distinguished into two categories, based on the method of disassembly, non-destructive disassembly (dismantling) and destructive (shredding). Non-destructive disassembly can be divided into total disassembly and selective disassembly (Desai and Mital, 2003).

From end-of-life vehicles, dismantling companies first remove the oil, engine, transmission, tire, battery, catalytic converter, and other parts, which are commonly recycled or reused. Shredding companies then sort out the ferrous and non-ferrous metals and resin from the remaining vehicle bodies. While the ferrous and non-ferrous metals are recycled, the shredder residue is being disposed of as waste in landfills (Toyota Motor Company, 2005). Figure 1 shows this process.

In order to most effectively utilize the earth's resources and reduce the volume of disposable waste, automobile recycling activities must include efforts to further reduce the volume of this waste and promote its reuse and recycling to ultimately achieve zero waste.

According to Joshi, Venkatachalam and Jawahir (2006), shifting from the 3R concept (reduce, reuse, recycle) to the 6R concept (reduce, remanufacture, reuse, recover, recycle, redesign) may result saving gains for both manufacturers and consumers. Figure 2 describes this concept. In order to enhance this $6 \mathrm{R}$ effort and to make it more cost effective, based on the review of the literatures, it is essential to integrate the $6 \mathrm{R}$ criteria into all phases of the vehicle development process.

\subsection{Current Environmental Tools used for Strategic Guidance in Design}

There are several tools and techniques that can help guide designers in the design process and also influences the resultant design in a proactive environmental way. The main tools are life Cycle Costing, Value Analysis and Eco Design:

\section{a. Life Cycle Costing (LCC)}

LCC is a method of analysis used when quantifying the cost related to the product during its life cycle. Woodward (1997) defined LCC as the sum of all funds expended in support of the items from its conception and fabrication, through its operation, to the end of its useful life. It is clear that, the cost of End-of-Life (EOL) is one of main the elements in LCC. That means the cost of EOL has to be considered at an early stage of the product development process. This is to optimise the total cost for each process and also to optimise the value for money for any investment.

It is important because management can realise the source and magnitude of lifetime cost so that effective action can be taken. This approach encourages a long-term outlook for the investment decision-making process. Based on this, the concept of LCC can assist a designer to predict the EOL cost at the early conceptual design stage.

According to Westkemper, Niemann and Dauensteiner (2001), the LCC is the new cost accounting method to assess the share of costs and revenues. It can be used in order to assess the increasing expenditures during the use, service and disposal phases. A minimum of the total cost and a maximum of benefit are achieved when considering the costs of production, installation use and disposal.

The main elements of LCC are the production, usage (market) and disposal (deproduction). It is clear that, the costs and revenues for recycling processes must be carefully considered during the early stages of product development. This is in order to produce the right model for disposal at the end of the LCC. Figure 3 shows the relationship of these elements.

\section{b. Value Analysis}

Value analysis is a functional approach that identifies the necessary and unnecessary costs such as reducing the number of components in order to reduce the assembly time. For example, by just considering a simple vehicle component such as bumper there are various possible combinations of processing or reprocessing this component. Value analysis can investigate the functionality of each part, material, structure etc. in order to reduce the costs and increase revenue in terms of quality, safety, recyclability etc.

Value analysis is not an easy task, especially in the area of recycling purposes as there are a lot of factors that influence the performance of the recycling process. It is usually considered during the early stages of product development and the target for when the product reaches an EOL situation is typically 13 years later (Motorparc, 1997). Any design decision now can forecast the impact to the performance of recyclability of the product in 13 years time. Therefore, without any proper analysis and consideration, the precise model for recyclability performance can be difficult to develop especially if the analysis involves investments considerations (i.e. costs and revenue aspects).

Currently, the most common tools in making decisions for any investment are Future Worth, Annual Worth, Rate of Return, Benefit-Cost Ratio, Net Present Value, Return of Investment and Payback Period. All of these methods are well documented by Meredith and Suresh (1986). Based on their survey, the majority of the firms (about 91\%) use Payback Period (PP) and Return of Investment (ROI) as an economic justification approach.

\section{c. Eco Design}


Eco Design is a design process in which environmental attributes are treated as design objectives rather than as constraints. It is incorporates environmental objectives with minimum loss to product performance, useful life or functionality (U.S. Congress, 1992). It is one of the key elements in design tools especially in the areas of Design-for-X (DFX) such as Design-for-Environment (DFE), Design-for-Recycling (DFR) and Design-for-Disassembly (DFD).

Basically, it is the front-end planning discipline that simultaneously takes into account impacts of design, manufacturing, use and disposal of product on the environment. It covers the wide areas of current design requirements such as health and safety, service life, toxicity, recycled content of manufacturing materials s, reuse of products, recyclability of products, energy use, manufacturing wastes and disposal alternatives (ASME, 1994).

Related to these, several approaches have been described in the literature. Rose and Ishii (1999), propose an Internet based tool to guide designers to determine EOL strategies, called End-of-Life Design Advisor (ELDA). Knight and Sodhi (2000) present an analysis of materials separation, which determines the least cost or maximum profit level of materials separation.

Several others Eco Design approaches have been proposed. Viswanathan and Allada (2001), propose a Configuration Value (CV) model to evaluate and analyse the effect of configuration on disassembly. Meanwhile, Ernzer and Wimmer (2002), highlight the quantitative and qualitative methods to reduce the environmental burden of products.

Recently, Xu, Lam and Tang (2004), developed a green design automation system. This is a computational design tools that plays an active part in environmental conscious design and development. Sakita, Mori and Igoshi (2004), propose the functions of computer aided design and simulation systems for the conceptual design of environmentally conscious products.

The literature mentioned above represents the current developments in the area of design tools for the environment taking account of cost/revenue issues. This previous work has been considered when the research team developed the strategic guidance model for product development relating to recycling aspects.

\subsection{Current Development Tools used for Strategic Guidance Specifically for ELVs}

Basically, there are two factors to influence that development of a Strategic Guidance model; cost and revenue relating to the recycling process. Several approaches to developing Strategic Guidance models for ELVs have been described in the literature. In recent years, research activity related to the recycling activities, has increased dramatically. This is because recycling activities are the key components of the ELV Directive (The European Parliament and of the Council of European Union, 2000).

Generally, there are many economic models that have been developed such as reported by Tipnis (1991). With the introduction of the concept of LCC, in relation with EOL issues, some of the conventional economic models need to be modified in order to fulfil the requirements of an EOL situation; to take account of environmental aspects, disassembly concepts and recycling activities.

In the early 90's, several economic model for recycling activities have been developed. Dieffenbach and Mascarin (1993), examined the cost and value associated with the vehicle recycling infrastructure using a technique called Technical Cost Modelling. It is a computer spreadsheet technique used by IBIS Associates for the simulation of process costs. Using this technique, several alternatives are developed for the recovery of plastics from scrapped vehicles based on varying a vehicle's material mix. This is to determine how best to recover the plastic materials. This model can help a designer to design the component to be more recyclable.

Meanwhile, Low, Williams and Dixon (1998), present the improved models of the economic analysis for manufacturing products with EOL consideration. They consider several options at the end of the first life of a product: resale, remanufacture, upgrade, recycling and scrap. The option model that has been developed is compared with current commercial data and it is then used to generate the empirical constants for elements of each model. The effects of the design changes on the financial impacts of EOL operations have been modelled based on several design alternatives of a telephone. The results, based on the analysis, shows that a strategy that increases recycling operations is likely to reduce the overall net revenue and the effect of the increasing take back costs also contributes to a negative revenue gradient. Johnsons and Wang (1998), introduced a procedure, which integrates economical factors into the scheduling of disassembly operations for Materials Recovery Opportunity (MRO). An MRO is defined as an opportunity to reclaim post-consumer products for recycling, remanufacturing and reuse. The outcome of this study is a determination of the most economical level of product disassembly and the corresponding sequence of disassembly operations. This is in order to improve the current disassembly process by reducing disassembly time and maximising profitability.

Several other Strategic Guidance approaches have been proposed. Veerakamolmal and Gupta (1999) present a technique to analyse the efficiency of designing electronic products for the environment. The efficiency of each design is indicated using Design for Disassembly Index (DfDI) to measure the economic efficiency of the recycling process. This technique involves the analysis of the trade-off between the costs and benefits of end-of-life disassembly to find 
the combination of components that provides the optimum cost-benefit ratio for end-of-life retrieval. The cost considerations include the costs of disassembly (labour) and disposal, while the benefit is derived from the sale of recovered components and materials. The index offers a designer an important measure to help improve the future design of products.

Recently, a Strategic Guidance model was developed by Harrison and Blount (2000) and also Vogtlander, Bijma and Brezet (2002). Harrison and Blount developed a new tool for evaluating automotive recyclability in the design process, within a whole life cost methodology. This model has adapted the life cycle analysis techniques to give special consideration for recyclability and costing of alternatives automotive design strategies. Furthermore, this model can assist the automotive designers to design a more recyclable vehicle and incorporates the economic viability of the recycling process at the design stage.

Vogtlander, Bijma and Brezet presents a new model to describe the sustainability of products. This model is called the Eco-cist/Value Ratio (EVR). It comprises of two concepts: the 'virtual eco-cost' as a LCA-based single indicator for environmental impact and the Eco-cist/Value Ratio (EVR) as an indicator for eco-efficiency.

The result of the literature review shows that there is a need for a model for Strategic Guidance for the automotive designers and the recycling industry, in order to successfully implement the ELV Directive. This aspect must be considered and evaluated more rigorously early on in the product design process. This scenario can help the automotive designers to design a more recyclable vehicle and enable economic viability of the recycling process.

\section{The Methodology for Strategic Guidance to Optimise recycling in Product Development}

The principle of the overall methodology for a Strategic Guidance model can be divided into four stages. These are the business strategy stage, evaluation stage, financial justification stage and the decision stage as shown in Figure 4 below.

\section{i. Business strategy stage}

The first step is to set the target of return or indicator for each vehicle or components that has been developed. The target of return or indicator means the value of that particular vehicle or components when its reaches EOL. Coinciding this, the competitors' performance must be analysed in order to produce a concrete strategy. After that, the availability of the facilities must be checked, in terms of technology, infrastructure, operator skills, company facilities and also external partnerships (e.g. recycling company, local authority etc.).

ii. Evaluation stage

This stage evaluates the performance of each facility in terms of process efficiency.

\section{iii. Financial justification stage}

This is the most important stage in the development of a Strategic Guidance model. Every single cost involved, such as direct cost and indirect cost must be clearly analysed. This is in order to get the right decision for any investment.

iv. Decision stage

Finally, the investment decision can be decided using the Payback Period method.

The Payback Period method is a logical way of making decisions based upon the probable outcome of various scenarios of action. Uncertainty and choice are attributes of every decision made, with the best option aimed at reducing risks and evaluating the cost and revenue implications of a new investment.

\section{Development of Strategic Guidance Model for Value Analysis and Investment Appraisal}

The Strategic Guidance model gives the user a clear idea of what is being considered, together with the specification of all assumptions made, combined with the rational behind all assumptions. The estimates of all expected costs such as direct and indirect associated with the recycling process is clearly identified as shown in Figure 5.

The model encompasses two main analyses: value analysis and financial analysis. The main objective of the proposed model is to be a vehicle design advisor. Although it can also be used to assist more strategic management decisions concerning recycling; as it provides a tool for measurement of business performance, in the recycling area, if a business is planning for investment in that area in the future.

The first path of the framework is Value Analysis for EOL as a design assessment tool. Details of this analysis are reported by Mat Saman et al. (2004) and are shown in Figure 6.

The outcome of this analysis is to determine the performance of the current design. This performance is given an indicator. In addition, the total operating cost and total revenue can also be determined.

There are six steps in the proposed framework of the value analysis, which encompasses three main principal operations as summarised in Table 3. Basically, three principal parameters will be considered in the proposed framework, i.e. reuse (including remanufacturing and reconditioning aspects), recycling for high-grade materials and also low-grade materials, 
recovery and waste analysis. The detailed analysis for each parameter is based on the unit weight of the automotive components. When the initial analysis has been done, the measurement parameters can be determined based on costs and revenues. In this case, there are three measurement parameters; acquisition (purchase, handling and fee processes), dismantling (reuse, remanufacturing, reconditioning and de-pollution processes) and also shredding (recycling, recovery and waste processes).

Finally, the measurement parameters will be translated into a total indicator to show the ELV performance of the design process for each component or the whole vehicle. The indicator shows the performance of the current design when that vehicle, or its components, reaches end-of-life (EOL). The reference point here is zero. That means, at EOL there is no value for that particular design. The best value here is a positive value. The concept used is that the biggest value of the indicator is the best design. So, this value can be used in order to improve the future design.

Meanwhile, the total operating cost and total revenue will be produced when considering the capacity of the facilities for processing ELV per year. Based on these two values, the net profit can be determined. The second path is a development of financial analysis for strategic guidance and the development of an advisory mode to achieve a defined return. The purpose of this analysis is to determine the total investment cost to build-up a recycling facility. Based on the total investment cost and net profit, the investment appraisal can be evaluated using a payback period method. In the calculation of the investment appraisal, it assumed that there will be a $100 \%$ utilisation of each facility for the products being analysed.

\section{Case Study}

As the case study an ELV is chosen. In general, the steps in Figure 5 are followed. It can be divided into two analyses, value analysis and financial Analysis. Value analysis calculation is based on the steps in the Figure 6. A financial analysis is done by using a payback period method.

1) Value analysis

\section{Step 1: General Characteristics of the ELV}

The first step is to determine the general characteristics of the ELV. This information is very important for the general overview of the case study. The general characteristic of the ELV which are analyzed is as follow.

Vehicle $=$ Jaguar

Total weight $=1576 \mathrm{~kg} / \mathrm{ELV}$

Part $=$ Whole vehicle

Income of vehicle $=£ 35 / \mathrm{ELV}$

Analyses $=$ Current design

\section{Step 2: Determination of the Reused Content}

The objective of this step is to determine the preliminary estimates for the reused analysis. This step is divided into 5 sub steps.

\section{A. General Information of the ELV}

Quantity of the ELV's (unit) $=1$

Quantity of the ELV's (kg) $=1576$

Average $\%$ of part studied $=(1576 / 1576) \times 100 \%=100 \%$

B. Content Based Material Categories of Original ELV

$\begin{array}{lll}\text { Quantity of ferrous materials }(\mathrm{kg}) & =1017.50 \\ \text { Quantity of nonferrous materials }(\mathrm{kg}) & =187.10 \\ \text { Quantity of plastic materials }(\mathrm{kg}) & =180.00 \\ \text { Quantity of high value materials }(\mathrm{kg}) & =37.20 \\ \text { Quantity of others materials }(\mathrm{kg}) & =84.00 \\ \text { Quantity of electrical materials }(\mathrm{kg}) & =21.40 \\ \text { Quantity of hazardous materials }(\mathrm{kg}) & =48.80 \\ \text { Total } & =1576\end{array}$

C. Fraction of Components or Parts Recovered

Expected $\%$ of reused components or parts $=25$ 
Expected $\%$ of recycled components or parts $=75$

D. Nominal Mass of Components or Parts

Reused components or parts $(\mathrm{kg})=$ Expected $\%$ of reused components or parts $\mathrm{x}$ Total weight of part $(\mathrm{kg})=25 \% \mathrm{x} 1576$ $=394$

Recycled components or parts $(\mathrm{kg})=$ Expected $\%$ of recycled components or parts $\mathrm{x}$ weight of part $(\mathrm{kg})=75 \% \mathrm{x} 1576=$ 1182

\section{E. Content Based Categories of Reused Components or Parts}

Quantity of components or parts (original) $(\mathrm{kg})=294$

Quantity of components or parts (remanufacture or reconditioning) $(\mathrm{kg})=100$

Step 3: Determination of the Recycled Contents

After the reused components or parts have been determined, the balance goes to the recycling analysis. The details of this step are as follows:

F. Content Based Material Categories of Recycled Components or Parts

$\begin{array}{lll}\text { Quantity of ferrous materials }(\mathrm{kg}) & =890.5 \\ \text { Quantity of nonferrous materials }(\mathrm{kg}) & =107.10 \\ \text { Quantity of plastic materials }(\mathrm{kg}) & =60 \\ \text { Quantity of high value materials }(\mathrm{kg}) & =0 \\ \text { Quantity of low value materials }(\mathrm{kg}) & =75.60 \\ \text { Quantity of hazardous materials }(\mathrm{kg}) & =48.80 \\ \text { Total (kg) } & =1182\end{array}$

\section{G. Fraction of Materials Recovered}

Expected $\%$ of ferrous materials $=95$

Expected \% of nonferrous materials $=95$

Expected $\%$ of plastic materials $=0$

Expected $\%$ of high value materials $=0$

Expected $\%$ of low value materials $=0$

Expected $\%$ of hazardous materials $=100$

Resulting $\%$ of wasted materials $=100$

\section{H. Nominal Mass of Materials}

Ferrous materials $(\mathrm{kg})=$ Expected \% of ferrous materials $\mathrm{x}$ Quantity of ferrous materials $(\mathrm{kg})=95 \% \mathrm{x} 890.5=845.975$

Nonferrous materials $(\mathrm{kg})=$ Expected \% of nonferrous materials $\mathrm{x}$ Quantity of nonferrous materials $(\mathrm{kg})=95 \% \mathrm{x}$ $107.10=101.745$

Plastic materials $(\mathrm{kg})=$ Expected \% of plastic materials x Quantity of plastic materials $(\mathrm{kg})=0 \%$ x $60=0$

High value materials $(\mathrm{kg})=$ Expected $\%$ of high value materials $\mathrm{x}$ Quantity of high value materials $(\mathrm{kg})=0 \% \mathrm{x} 0=0$

Low value materials $(\mathrm{kg})=$ Expected $\%$ of low value materials $\mathrm{x}$ Quantity of low value materials $(\mathrm{kg})=0 \% \mathrm{x} 75.60=0$

Hazardous materials $(\mathrm{kg})=$ Expected $\%$ of hazardous materials x Quantity of hazardous materials $(\mathrm{kg})=100 \% \times 48.80$ $=48.80$

Waste materials $(\mathrm{kg})=1182-(845.975+101.745+48.80)=185.47$

Step 4: Determination of the Recovery and Waste Contents

There are two possibilities here for the ELV; either going to the landfill as waste or to be used for a useful purpose such as energy recovery, road surfacing etc. The weight of the ELV to be land filled or used for another purpose is determined here.

\section{Fraction of Waste Materials Recovered}

Expected $\%$ of landfill $=100$

Expected $\%$ of useful purpose $=0$ 


\section{J. Nominal Mass of Waste Materials}

Landfill $=$ Expected $\%$ of landfill $\times$ Waste materials $(\mathrm{kg})=100 \% \times 185.47=185.47$

Useful purpose $=$ Expected $\%$ of useful purpose $\mathrm{x}$ Waste materials $(\mathrm{kg})=0 \% \mathrm{x} 185.47=0$

Step 5: Value Analysis

This step has been developed based on the three main analyses. There are acquisition analysis, dismantling analysis and also shredding analysis. Each part of the analysis has data for the costs and also revenues for every process, every component or every material involved. Based on that, the return for each analysis can be calculated.

\section{K. Acquisition}

\section{Acquisition Data:}

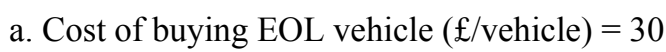

b. Payment from vehicle manufacturer or local authority $(£ /$ vehicle $)=35$

\section{Acquisition Cost:}

Proportion for new vehicle $(\mathfrak{£})=27$

Total acquisition cost $(\mathfrak{f})=27$

\section{Acquisition Revenue}

Proportion for new vehicle $(\mathfrak{E})=3.5$

Total acquisition revenue $(\mathfrak{f})=3.5$

Total profit of acquisition $(\mathfrak{E})=$ Total acquisition revenue $(\mathfrak{f})$ - Total acquisition cost $(\mathfrak{f})=3.5-27=-23.5$

\section{Dismantling}

\section{Data of the Dismantling Process}

Cost of dismantling processes $(\mathfrak{f} / \mathrm{kg})=0.05$

Cost of disposing of hazardous materials $(\mathfrak{f} / \mathrm{kg})=0.10$

Market price of spare part components (original) $(\mathfrak{£} / \mathrm{kg})=0.20$

Market price of spare part components (remanufacture or reconditioning) $(£ / \mathrm{kg})=0.10$

Costs of Dismantling Process

Dismantling processes $(\mathfrak{E})=$ Cost of dismantling processes $(\mathfrak{f} / \mathrm{kg}) \times$ Reused components or parts $(\mathrm{kg})=0.05 \times 394=$ 19.7

Disposing of hazardous materials $(\mathfrak{f})=$ Cost of disposing of hazardous materials $(\mathfrak{f} / \mathrm{kg}) \times$ Nominal mass of hazardous materials $(\mathrm{kg})=0.1 \times 48.8=4.88$

Total Dismantling Cost $(\mathfrak{E})=$ Cost of Dismantling processes $(\mathfrak{E})+$ Cost of disposing of hazardous materials $(\mathfrak{E})=19.70$ $+4.88=24.58$

\section{Revenue of Dismantling}

Spare parts components (original) $(\mathfrak{E})=$ Market price of spare part components (original) $(\mathfrak{f} / \mathrm{kg}) \times$ Quantity of components or parts (original) $(\mathrm{kg})=0.20 \times 294=58.8$

Spare parts components (remanufacture or reconditioning) $(\mathfrak{E})=$ Cost of disposing of hazardous materials $(\mathfrak{f} / \mathrm{kg}) \mathrm{x}$ Quantity of components or parts (remanufacture or reconditioning) $(\mathrm{kg})=0.10 \times 100=10$

Total Revenue of Dismantling $(\mathfrak{f})=$ Revenue of spare parts components (original) $(\mathfrak{f})+$ Revenue of spare parts components (remanufacture or reconditioning) $(\mathfrak{f})=58.8+10=68.8$

Total Profit of Dismantling $=$ Total Revenue of Dismantling - Total Dismantling Cost $=68.8-24.58=44.22$

\section{Shredding}

Data of Shredding

Cost of shredding processes $(\mathfrak{£} / \mathrm{kg})=0.05$

Cost of disposing of waste (landfill cost) $(£ / \mathrm{kg})=0.01$

Market price of ferrous materials $(\mathfrak{f} / \mathrm{kg})=0.12$

Market price of nonferrous materials $(£ / \mathrm{kg})=0.22$

Market price of plastic materials $(\mathfrak{£} / \mathrm{kg})=0.10$ 
Market price of the other materials $(£ / \mathrm{kg})=0.01$

Market price of waste materials for useful purpose $(\mathfrak{f} / \mathrm{kg})=0.04$

Costs of shredding

Shredding processes $(£)=$ Cost of shredding processes $(£ / \mathrm{kg}) \times$ Total of Content Based Material Categories of Recycled Components or Parts $=0.05 \times(890.5+107.10+60+0+75.60+48.8)=59.10$

Disposing of waste (landfill cost) $(\mathfrak{f})=$ Cost of disposing of waste (landfill cost) $(\mathfrak{f} / \mathrm{kg}) \mathrm{x}$ Nominal mass of waste materials $(\mathrm{kg})=0.01 \times 185.47=1.8547$

Total Cost of shredding $(£)=$ Cost of shredding processes $(£)+$ Cost waste disposal (landfill cost $)(£)=59.10+1.8547$ $=60.95$

\section{Revenues of shredding}

Ferrous materials $(£)=$ Market price of ferrous materials $(£ / \mathrm{kg}) \times$ Nominal Mass of Ferrous materials $(\mathrm{kg})=0.12 \mathrm{x}$ $845.98=101.52$

Nonferrous materials $(£)=$ Market price of nonferrous materials $(£ / \mathrm{kg}) \times$ Nominal mass of nonferrous materials $(\mathrm{kg})=$ $0.22 \times 101.75=22.39$

Plastic materials $(£)=$ Market price of plastic materials $(£ / \mathrm{kg}) \times$ Nominal mass of plastics materials $(\mathrm{kg})=0.10 \times 0=0$

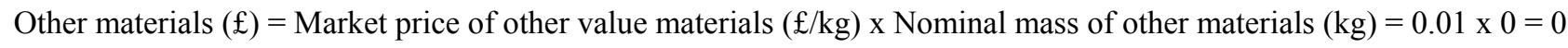

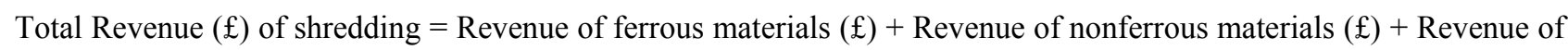
plastic materials $(£)+$ Revenue of other materials $(£)=101.52+22.39=123.91$

Total Profit of Shredding $(\mathfrak{f})=$ Total revenue of shredding - Total cost of shredding $=123.91-60.95=62.96$

\section{Step 6 Indicator}

After completing an analysis in step 5, the grand total of the return for acquisition, dismantling and also shredding can be calculated. This value is called as the indicator

$N$. Grand Total of $K+L+M=$ Total profit of acquisition $(\mathfrak{E})+$ Total profit of dismantling + Total profit of shredding $(£)=-23.5+44.22+62.96=83.67$ (Indicator)

2) Financial Analysis

In the financial analysis, it is assumed that the capacity of the recycling company is $1000 \mathrm{ELV} /$ year. So that the profit generated by the company is about $83.67 \times 1000=836700 /$ year. The details of the investment invested by the company are as follows:

\section{Investment}

Land and Building

Weighbridge

Environment lock

Forklift

Dismantling equipment

Truck

Crusher

Container/skip

Engine hoist

Trolley jack

Skip loading

Total

\section{Quantity Cost (£)/ Investment Cost (£)}

$$
\text { unit }
$$

$\begin{array}{ll} & 2,200,000 \\ 60,000 & 60,000 \\ 100,000 & 100,000 \\ 20,000 & 100,000 \\ 600,000 & 600,000 \\ 90,000 & 270,000 \\ 30,000 & 30,000 \\ 2,000 & 20,000 \\ 500 & 2,500 \\ 300 & 1,500 \\ 15,000 & 15,000\end{array}$

Payback period $($ year $)=(3399000 / 836700 /$ year $)=4.06$ years

\section{Results and Discussion}

Based on the result of the case study, it shows that, normally, the company is paid $£ 35 /$ vehicle, although (according to a UK recycler) currently only $10 \%$ of the time this situation happens. Besides that, if the owner sends the ELV to the recycling company, the company will pay $£ 30 /$ vehicle. Based on that data, the total cost and total revenue per vehicle 
are $£ 27.00$ and $£ 3.50$ respectively. Then, the return for the acquisition process is $-£ 23.50$. That means the acquisition process is currently not profitable to the company.

The return for the dismantling process is $£ 44.22 /$ vehicle. For the shredding process, the return is $£ 62.96 /$ vehicle. Both of these processes give some profit to the company. The grand total is $£ 83.67 /$ vehicle. It shows that the current design of the vehicle is valuable when it reaches EOL. This value can be used as an indicator for the future design of the vehicle.

The result from the value analysis will be transferred into the financial analysis for the investment appraisal. In the financial analysis, it is assumed that, the capacity of the recycling company is $10000 \mathrm{ELV} / \mathrm{year}$. The company generates a net of $£ 836700 /$ year. Meanwhile, the total investment for the whole site is $£ 3399000$. So based on this data, the payback period is calculated around 4.06 years.

\section{Conclusions}

The Strategic Guidance model presents a design assessment for the recyclability of a vehicle at the initial design stage. It assists automotive designers to identify the performance of the current design in terms of costs and revenue at EOL. The result from the analysis can also be used as guidance tool in order to improve the performance of the vehicle design in terms of recyclability aspects and at the same time to fulfil the ELV Directive. Besides that, the strategic guidance model is an advisory tool to a recycling company in order to determine a defined return.

The case study presented shows that the current design of that product has some value for recyclability. The detailed analysis highlights the performance of the investment in the recycling areas. The developed model is a tool to increase interaction between automotive designers and the recycling companies and also as a foundation for investment strategy for both types of business.

However, a further study will carried-out in the development of a methodology for design improvement. This is to provide a guidance and justification on how the vehicle components should be developed.

\section{References}

ASME. (1994). General Position Paper on Designing for the Environment of the American Society of Mechanical Engineers. Washington, USA, 2.

Desai, A. and Mital, A. (2003). Evaluation of Disassemblability to Enable Design for Disassembly in Mass Production. International Journal of Industrial Ergonomics, 16(7), 712-732.

Desai, A. and Mital, A. (2005). Incorporating Work Factors in Design for Disassembly in Product Design. Journal of Manufacturing Technology and Management, 32(4), 265-281.

Dieffenbach, J. R., Mascarin, A. E. and Fisher, M. (1993). Cost Simulation of the Automobile Recycling Infrastructure: the Impact of Plastics Recovery. SAE Paper, USA, 45-52.

Enzer, M. and Wimmer, W. (2002). From Environmental Assessment Results to Design for Environment Product Changes: an Evaluation of Quantitative and Qualitative Methods. Journal Engineering Design, 13(3), UK, 233-242.

Harrison, L. A. J. and Blount, G. N. (2000). Business Model Approach: Design versus Economic Considerations for Automotive Recycling. SAE 2000 World Congress, 2000-01-0666, USA, 97-101.

Johnson, M. R. and Wang, M. H. (1998). Economical Evaluation of Disassembly Operations for Recycling, Remanufacturing and Reuse. International Journal of Production Research, 36(12), UK, 3227-3252.

Joshi, K., Venkatachalam, A. and Jawahir, I.S. (2006). A New Methodology for Transforming 3R Concept into 6R Concept for Improved Product Sustainability. IV Global Conference on Sustainable Product Development and Life Cycle Engineering. São Carlos, Brazil.

Kanari, Pineau and Shallari. (2003). End of Life Vehicle Recycling in the European Union. Retrieved January 2008, from http://www.tms.org/pubs/journals/JOM/0308/Kanari-0308.html

Knight, W. A. and Sodhi, M. (2000). Design fro Bulk recycling: Analysis of Materials Separation. Annals of the CIRP, 49(1), USA.

Low, M. K., Williams, D. J. and Dixon, C. (1998). Manufacturing Products with End-of-Life Considerations: an Economic Assessment to the Routes of Revenue Generation from Mature Products. IEEE Transactions on Components, Packaging and Manufacturing Technology, Part C, 21(1), USA, 4-10.

Mat Saman, M. Z., Blount, G., Jones, R., Goodyer, J. and Jawaid, A. (2004). Framework of End-of-Life Vehicle (ELV) Value Analysis for Automotive Design Assessment. Proceeding of Fifth International Symposium of Tools and Methods of Competitive Engineering (TMCE2004), Switzerland.

Motroparc. (1997). World Automotive Statistics. SMMT Publication. 
PricewaterhouseCoopers LLP. (2002). The European Union End of Life Vehicle Directive is a Sensitive Issue for the global Automotive Industry", Retrieved December 2007, from http://www.pwcfr/fr/pwc_pdf/pwc_end_of_life.pdf.

Rose, C. M. and Ishii, K. (1999). Product End-of-Life Strategy Categorisation Design Tool. Journal of Electronics Manufacturing, 9(1), USA, 41-51.

Sakita, K., Mori, T. and Igoshi, M. (2004). Proposal of Computer Aided Design and Simulation System for Conceptual Design of Environmentally Conscious Products. Proceeding of Fifth International Symposium of Tools and Methods of Competitive Engineering (TMCE2004), Switzerland.

The European Parliament and of the Council of European Union. (2000). Directive 2000/53/EC of the European Parliament and of the Council of 18 September 2000 on End-of-Life Vehicles. Brusels: Official Journal of the European Communities, Belgium.

The European Parliament and of the Council of European Union. (2002). Commission Decision of 27 June 2002. Amending Annex II of Directive 2000/53/EC of the European Parliament and of the Council on End-of-life Vehicles. Brusels: Official Journal of the European Communities, Belgium.

The European Parliament and of the Council of European Union. (2005a). Directive 2005/64/EC of the European Parliament and of the Council of 26 October 2005 on the Type-approval of Motor Vehicles with Regard to their Reusability, Recyclability and Recoverability and Amending Council Directive 70/156/EEC. Brusels: Official Journal of the European Communities, Belgium.

The European Parliament and of the Council of European Union. (2005b). Commission Decision of 10 June 2005, Amending Annex II to Directive 2000/53/EC of the European Parliament and of the Council on End-of-life Vehicles. Brusels: Official Journal of the European Communities, Belgium.

The European Parliament and of the Council of European Union. (2005c). Council Decision of 20 September 2005, Amending Annex II of Directive 2000/53/EC of the European Parliament and of the Council on End-of-life Vehicles. Brusels: Official Journal of the European Communities, Belgium.

The European Parliament and of the Council of European Union. (2008). Directive 2008/33/EC of the European Parliament and of the Council of 11 March 2008, Amending Directive 2000/53/EC on End-of-life Vehicles, as Regards the Implementing Powers Conferred on The Commission. Brusels: Official Journal of the European Communities, Belgium.

Tipnis, V. A. (1991). Product Life Cycle Economic Models - Towards a Comprehensive Framework for Evaluation of Environment Impact and Competitive Advantage. Annals of the CIRP, 40(1), USA.

Toyota Motor Company. (2005). Recycling Initiatives. Retrieved July 2007, from http://www.toyota.co.jp/en/environment/recycle/state/index.html

U.S. Congress, Office of Technology Assessment. (1992). Green Products by Design: Choices for a Cleaner Environment. Washington, USA.

Veerakamolmal, P. and Gupta, S. M. (1999). A Combinatorial Cost-Benefit Analysis Methodology for Designing Modular Electronic Products for the Environment. International Symposium on Electronics and the Environment, USA.

Viswanathan, S. and Allada, V. (2001). Configuration Analysis to Support Product Redesign for End-of-Life Disassembly. International Journal of Production Research, 39(8), UK, 1733-1753.

Vogtlander, J. G., Bijma, A. and Brezet, H. C. (2002). Communicating the Eco-efficiency of Products and Services by Mean of the Eco-cost/Value Model. Journal of Cleaner Production, 10, UK, 57-67.

Westkamper, E., Niemann, J. and Dauensteiner, A. (2001). Economic and Ecological Aspects in Product Life Cycle Evaluation. Journal of Engineering Manufacture, 215(B5), UK, 673-681.

Woodward, D. G. (1997). Life Cycle Costing - Theory, Information Acquisition and Application. International Journal of Project Management, 15(6), UK, 335-344.

Xu, Z., Lam, Y. and Tang, M. (2004). Development of Green Design Automation System. Proceeding of Fifth International Symposium of Tools and Methods of Competitive Engineering (TMCE2004), Switzerland. 
Table 1. Summary of the ELV Directive (The European Parliament and of the Council of European Union, 2000, 2002, 2005a, 2005b, 2005c, 2008)

\begin{tabular}{|l|l|}
\hline Year & Event \\
\hline 2000 & $\begin{array}{l}\text { EU Directive on ELV was signed by the European Parliament and } \\
\text { Council of Ministers }\end{array}$ \\
\hline 2002 & Free of charge take back of new cars \\
\hline 2003 & Use of certain heavy metals forbidden: Cd, Cr(VI), Hg, Pb \\
\hline 2005 & $\begin{array}{l}\text { Type approval: OEMs have to prove that car meets } 2015 \\
\text { recycling/recovery quotas }\end{array}$ \\
\hline 2006 & $\begin{array}{l}\text { Dismantlers have to meet following quotas: } \geq 80 \% \text { recycling, } \leq 5 \% \\
\text { energy recovery, } \leq 15 \% \text { landfill }\end{array}$ \\
\hline 2007 & $\begin{array}{l}\text { Free of charge take back of all ELVs } \\
10 \% \text { energy recovery, } \leq 5 \% \text { landfill }\end{array}$ \\
\hline 2015 & \begin{tabular}{l} 
Dismantlers have to meet following quotas: $\geq 85 \%$ recycling, $\leq$ \\
\hline
\end{tabular} \\
\hline
\end{tabular}

Table 2. Recycling targets for the type-approval of new vehicles (The European Parliament and of the Council of European Union, 2000, 2002, 2005a, 2005b, 2005c, 2008)

\begin{tabular}{|l|l|l|}
\hline \multirow{2}{*}{ Year } & \multicolumn{2}{|l|}{ Targets for the type-approval of new vehicles } \\
\hline 1.1 .2005 & Reused and Recycling & $85 \%$ by weight per vehicle \\
\cline { 2 - 3 } & Reused and Recovery & $95 \%$ by weight per vehicle \\
\hline
\end{tabular}

Table 3. Summary of the main elements in the proposed framework

\begin{tabular}{|c|l|}
\hline \multirow{2}{*}{ Operation } & \multicolumn{1}{c|}{ Description } \\
\hline \multirow{2}{*}{ I } & ELV Background \\
\cline { 2 - 3 } & Step 1: General Characteristics of the ELV \\
\cline { 2 - 3 } & Preliminary Estimates \\
\cline { 2 - 3 } & Step 2: Determination of the Reused Contents \\
\cline { 2 - 3 } & Step 4: Determination of the Recovery and Waste Contents \\
\hline \multirow{2}{*}{ III } & ELV Indicator \\
\cline { 2 - 3 } & Step 5: Value Analysis \\
\cline { 2 - 3 } & Step 6: Determination of an Indicator \\
\hline
\end{tabular}




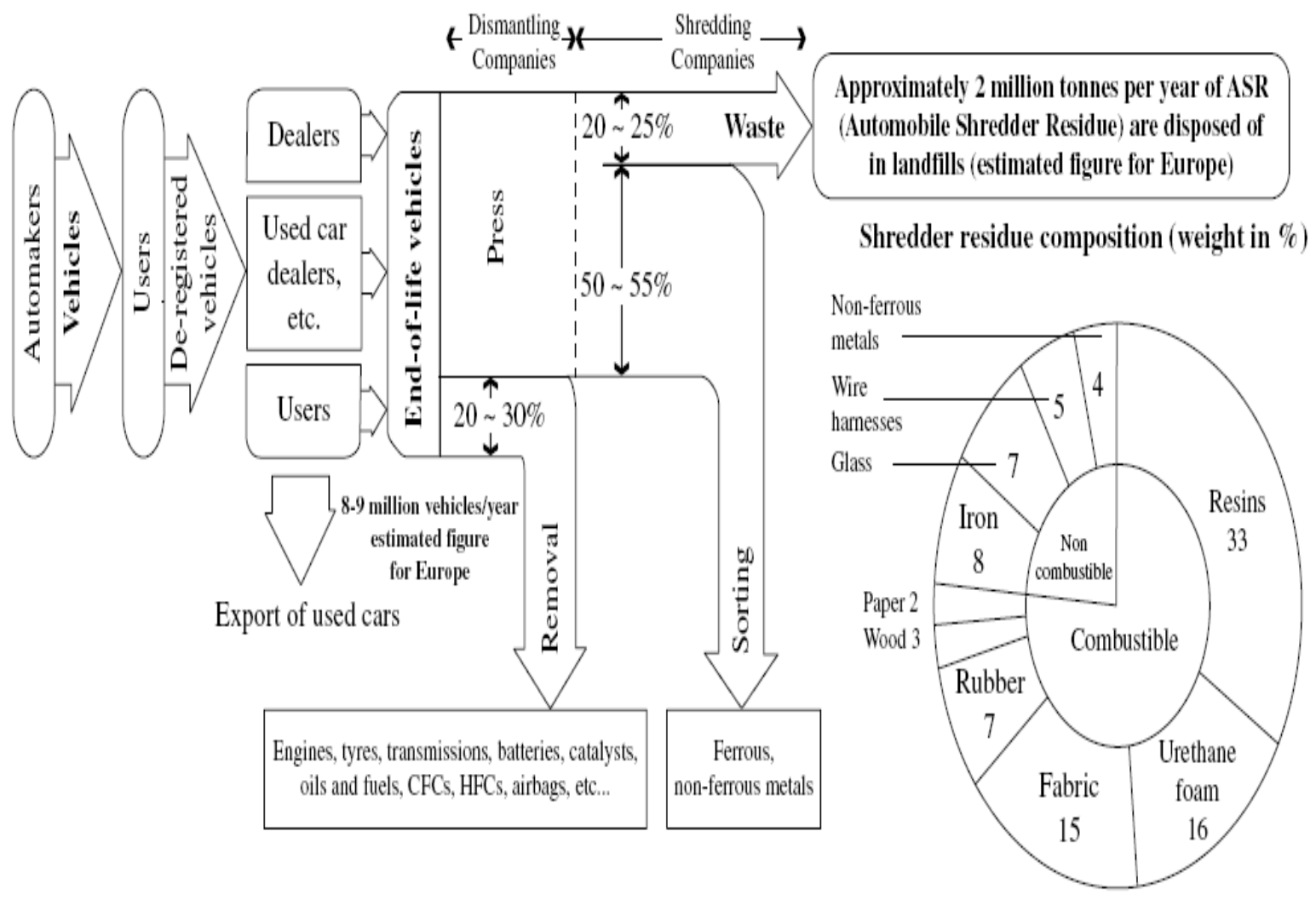

Figure 1. End-of-life vehicle recycling process

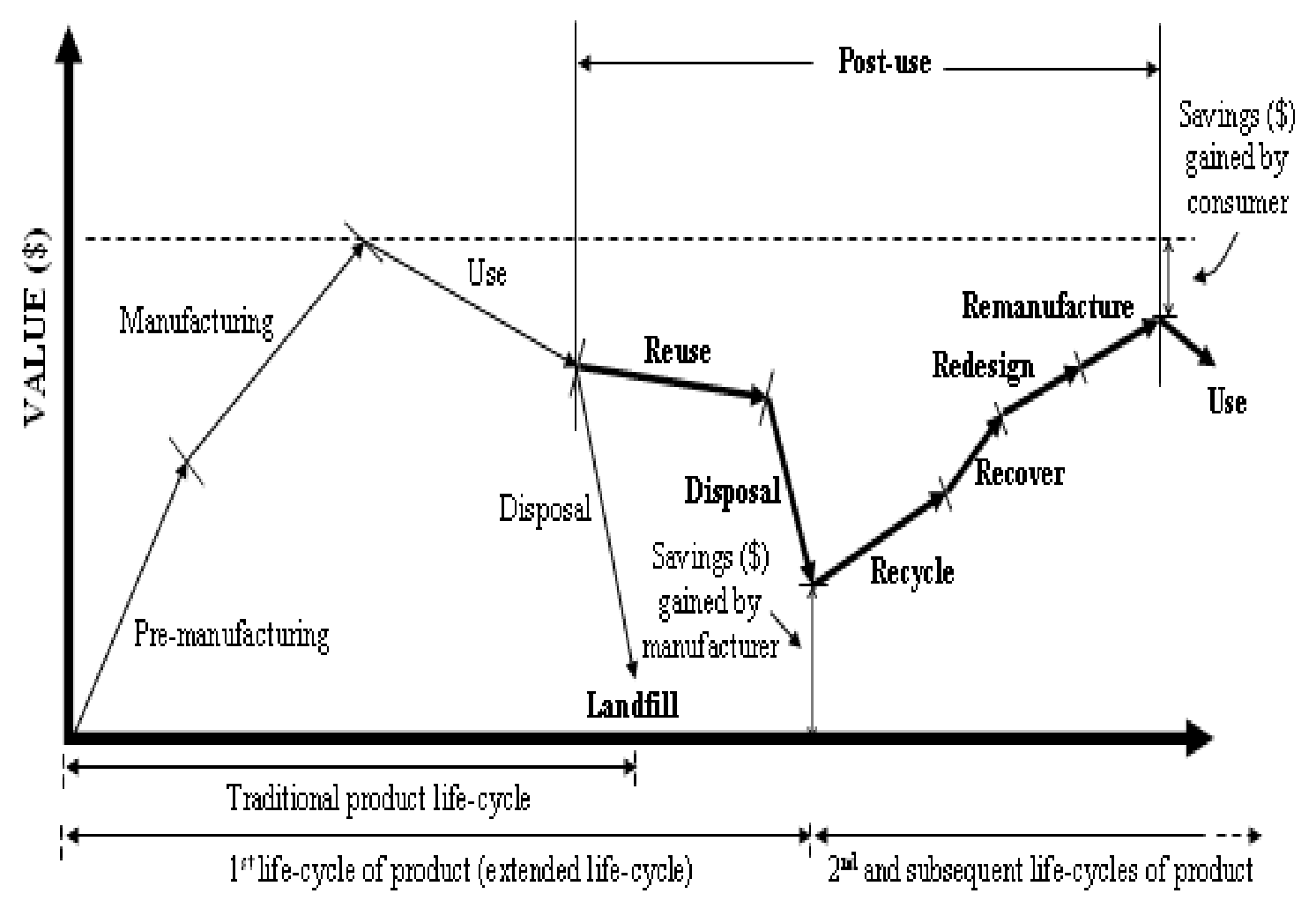

Figure 2. Product value gained from 6R (Joshi, Venkatachalam and Jawahir, 2006) 


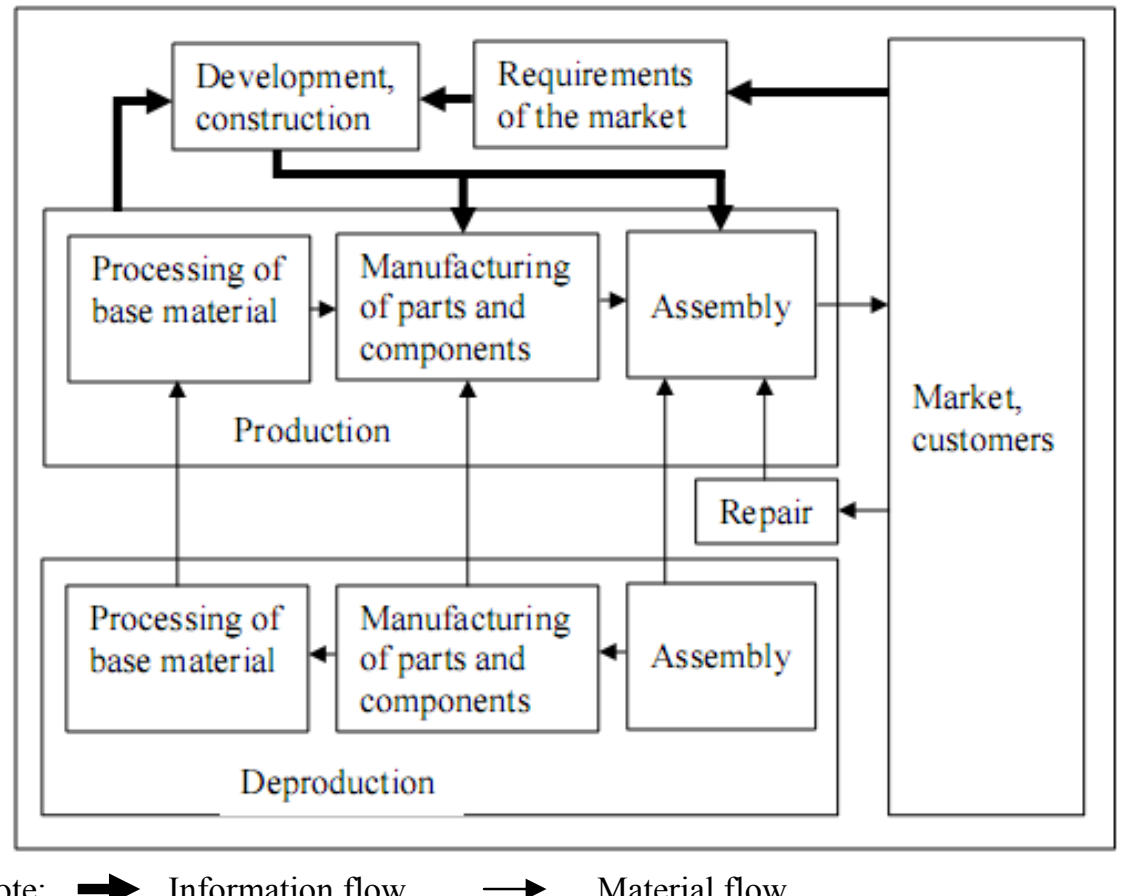

Note:

Information flow

$\rightarrow$ Material flow

Figure 3. The flows of the costs and revenues in LCC (Westkemper and Osten-Sacken, 1998)

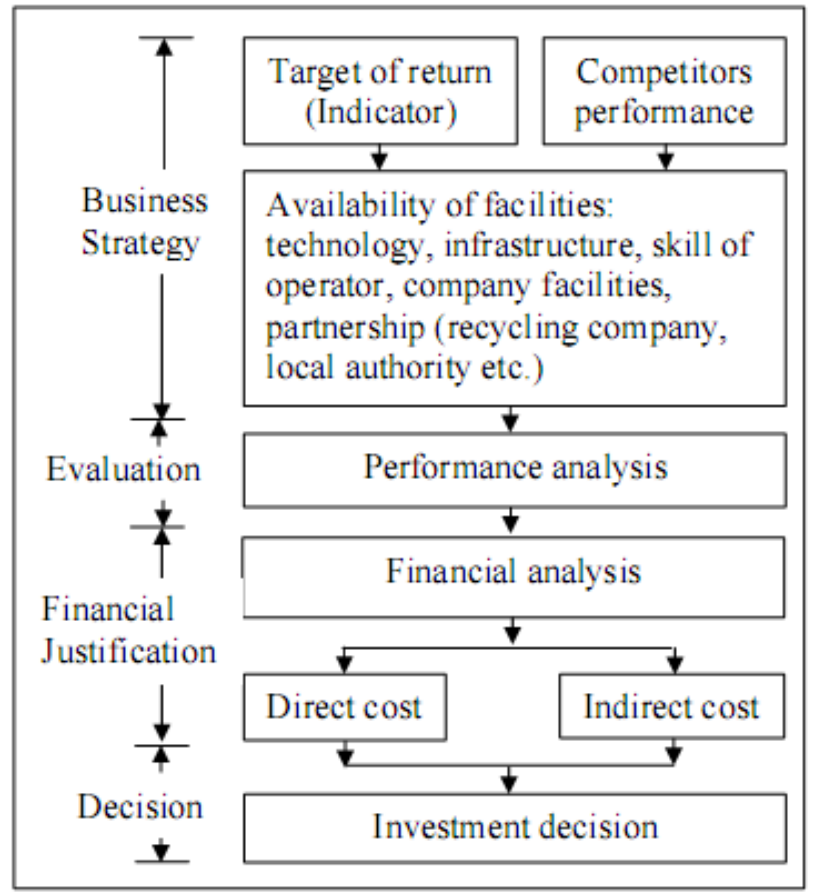

Figure 4. Principles of the study methodology for Strategic Guidance Model 


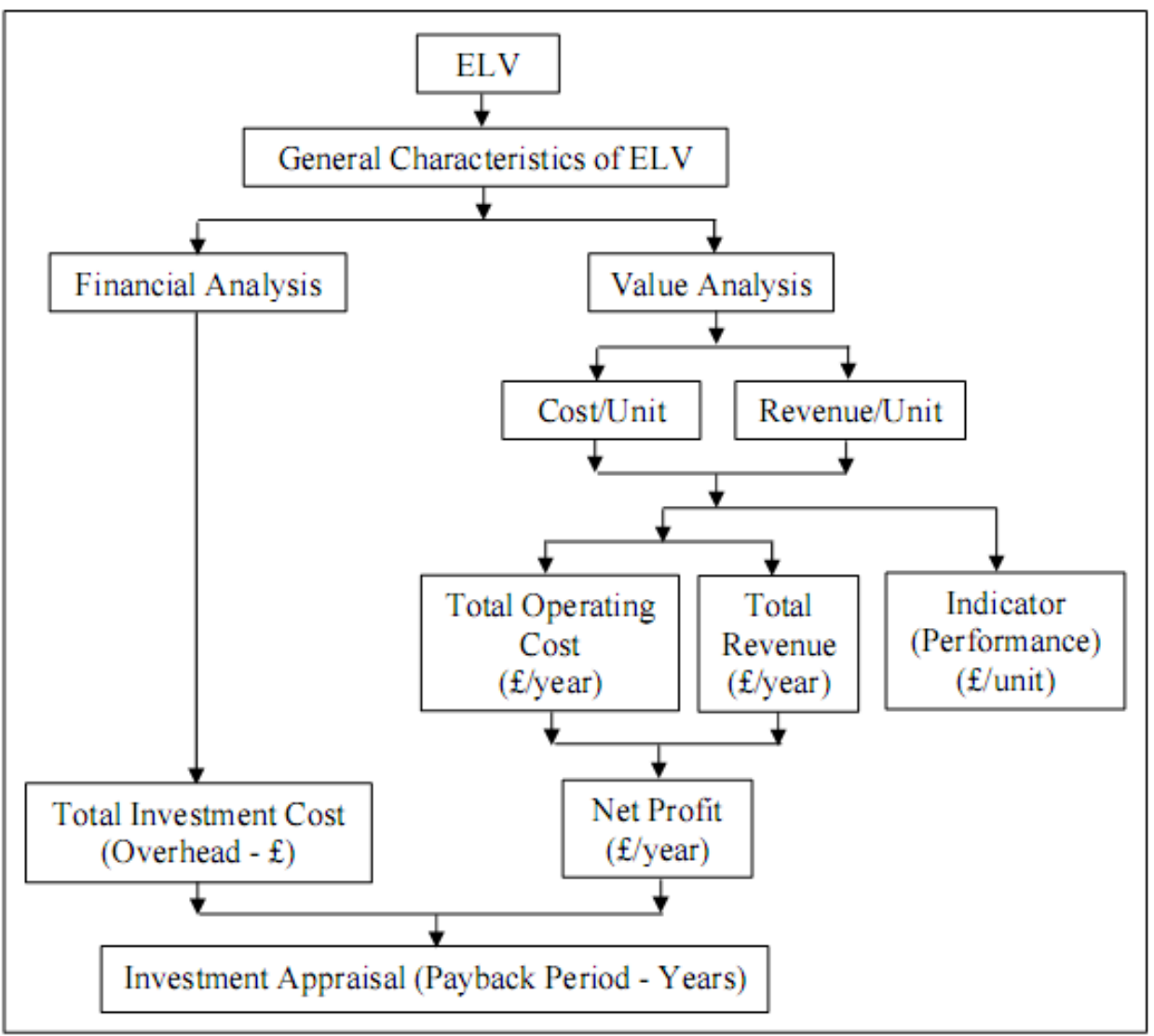

Figure 5. Strategic Guidance model 


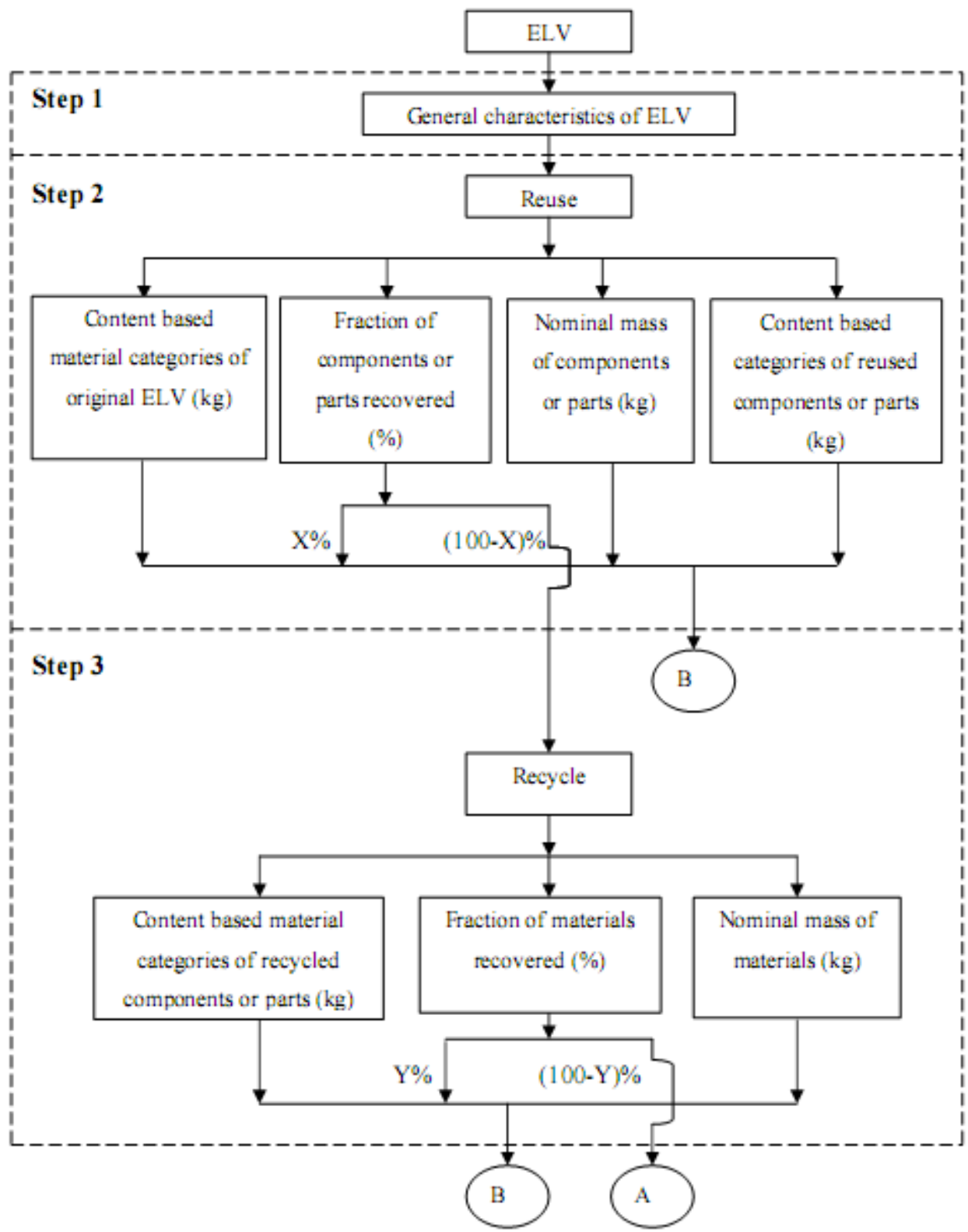

Figure 6. Framework for value analysis (continued overleaf) 


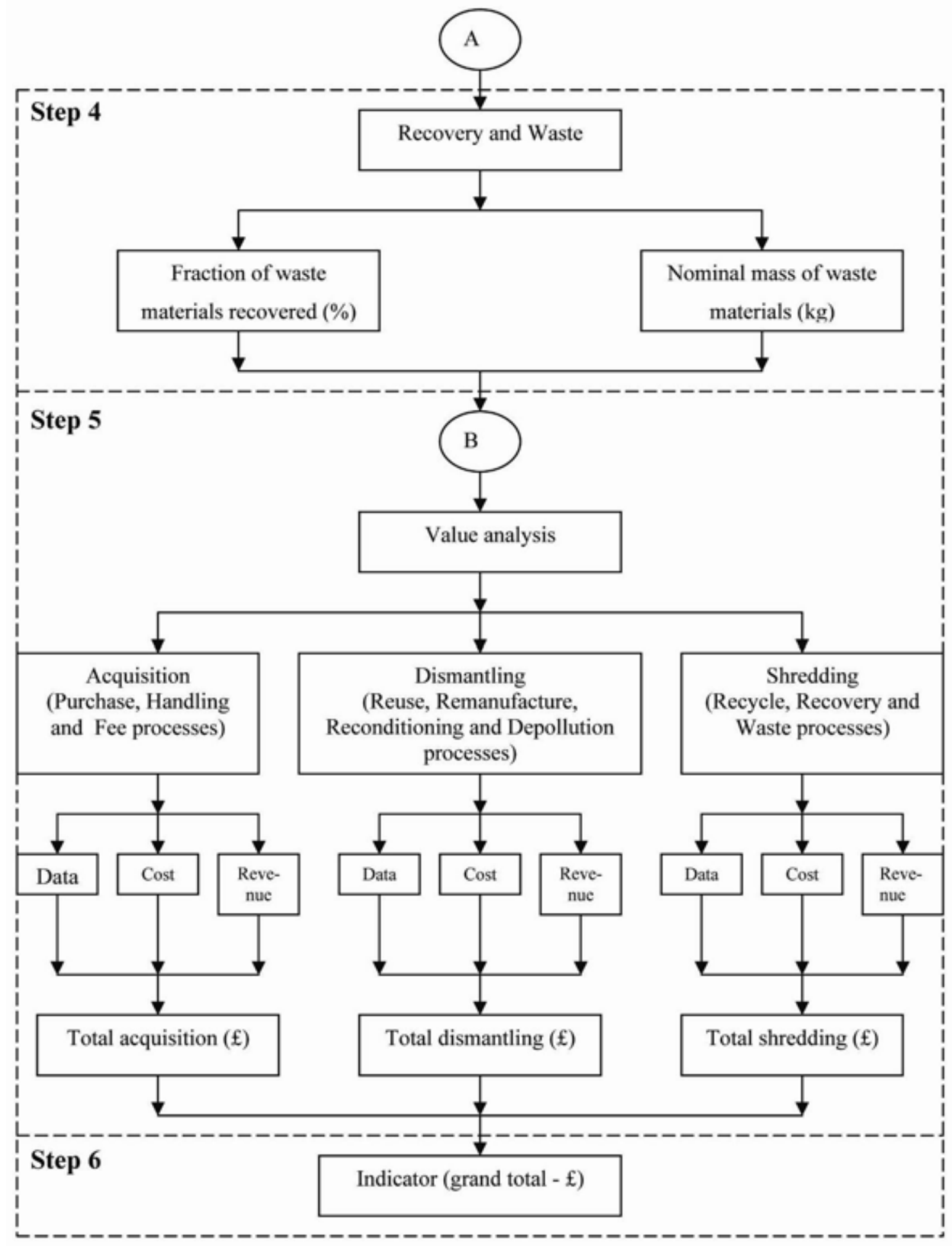

Figure 6. Framework for value analysis 